\title{
A pedagogia histórico-crítica e a defesa da transmissão do saber elaborado: apontamentos acerca do método pedagógico
}

\author{
Tiago Nicola Lavoura*
}

Ana Carolina Galváo Marsiglia**

\section{Resumo}

Este artigo possui como objetivo realizar uma discussão acerca do método pedagógico da pedagogia histórico-crítica, notadamente elucidando as bases de sua fundamentação referenciadas no Método da Economia Política elaborado por Marx na famosa Introduçáo de 1857. Desta feita, explicita-se o movimento do conhecimento como a passagem do empírico ao concreto pela mediação do abstrato, evidenciando o caráter mediador da educaçáo na prática social, tomando esta como ponto de partida e ponto de chegada do trabalho educativo, tendo-se como momentos intermediários do método pedagógico a problematização desta prática social, a instrumentalização por meio da transmissáo dos conhecimentos nas suas formas mais elaboradas e a catarse enquanto síntese de desenvolvimento do aluno e, consequentemente, a possibilidade de alteração da prática social humano-genérica. Assim, busca-se evidenciar a lógica dialética desta proposta pedagógica que defende a atividade de ensino na educação escolar como aquela responsável pela reprodução ideal do movimento real dos conteúdos escolares, permitindo o alcance da riqueza categorial dos objetos de ensino enquanto síntese de múltiplas determinações e relaçóes numerosas. Nesse sentido, compreender o método pedagógico dessa teoria em consonância com os fundamentos do materialismo histórico-dialético é essencial para sua realização bem sucedida e coerente com sua proposiçáo.

Palavras-chave: Educação Escolar. Pedagogia Histórico-Crítica. Método dialético.

* Doutor em Educação pela Universidade Federal de Minas Gerais (UFMG). Professor do Curso de Educação Física e da Pós-Graduação em Educação Física Escolar na Universidade Estadual de Santa Cruz (UESC).

** Doutora em Educação Escolar Universidade Estadual Paulista Júlio de Mesquita Filho (UNESP). Professora do Centro de Educação e do Programa de Pós-Graduação em Educação na Universidade Federal do Espírito Santo (UFES). 


\section{Introdução}

A sistematização e o desenvolvimento da pedagogia histórico-crítica vêm se dando, nestes mais de trinta e cinco anos de existência em nosso país, a partir da fundamentação teórico-metodológica da obra de Marx. É neste sentido que o professor Dermeval Saviani (2008a) situou esta teoria pedagógica enquanto expressão teórica do marxismo no campo da educaçáo.

Ao longo desses anos, é possível constatar críticas formuladas à pedagogia histórico-crítica, seja por autores conservadores e reacionários, representativos da elite dominante no campo educacional, seja até mesmo por parte de autores que se situam no interior do próprio campo marxista.

No ano de 2012, Dermeval Saviani e Newton Duarte lançaram a obra intitulada Pedagogia histórico-critica e luta de classes na educação escolar, objetivando responder às críticas e objeçóes dirigidas a essa teoria pedagógica, as quais na realidade não se constituem como novidade. Desde a primeira década de 1980, surgiram críticas a essa corrente pedagógica. Conforme retratado no prefácio da obra em questáo:

É interessante notar que nessas críticas se unem conservadores da direita e ultras da esquerda. Esses últimos consideram que ser crítico é ser intransigente, é negar inteiramente tudo o que a burguesia produziu, e assim acabam fazendo uma espécie de coro comum com a direita, fustigando a pedagogia histórico-crítica. (SAVIANI; DUARTE, 2012, p. 8).

Não é novidade para muitos a conhecida crítica a uma defesa inconteste da pedagogia histórico-crítica: a transmissão do saber elaborado. Critica-se, nesse sentido, uma de suas teses centrais, qual seja, a necessidade da educação escolar transmitir o conhecimento nas suas formas mais desenvolvidas.

Alguns críticos dessa pedagogia chegam a afirmar, por exemplo, a aproximação e, no limite, até mesmo a identificaçáo da pedagogia históricocrítica com a pedagogia tradicional, na medida em que em nada tais pedagogias se diferenciariam ao defender a transmissão de conteúdos de ensino. É exatamente dessa maneira que Tomaz Tadeu da Silva (1999, p. 63) reporta sua crítica:

[...] para Saviani, a tarefa de uma pedagogia crítica consiste em transmitir aqueles conhecimentos universais 
que são considerados como patrimônio da humanidade e não dos grupos sociais que deles se apropriam. [...] A análise de Saviani não se alinha nem mesmo com as análises marxistas, dominantes na época, que enfatizavam o caráter necessariamente distorcido - ideológico - do conhecimento, de modo geral, e do conhecimento escolar, de modo particular.

Inspirando-se nas análises de Michel Foucault, relacionando saber e poder, situando-se no quadro das teorias pós-estruturalistas, Silva (1999, p. 63) complementa:

No contexto das teorias pós-estruturalistas mais recentes, que assinalam, seguindo Foucault, um nexo necessário entre saber e poder, a teorizaçáo curricular de Saviani parece visivelmente deslocada. No limite, excetuando-se uma evidente intenção crítica, é difícil ver como a teoria curricular da chamada "pedagogia dos conteúdos" possa se distinguir de teorias mais tradicionais do currículo.

Entendemos que as críticas formuladas à pedagogia histórico-crítica, que acabam por situá-la no âmbito das "teorias mais tradicionais do currículo", como anteriormente apontado, em virtude de sua defesa da transmissão dos conhecimentos mais desenvolvidos e do saber elaborado, são oriundas da incompreensão de algo candente a esta pedagogia: a questão do método pedagógico.

O professor Dermeval Saviani já explicitou em várias oportunidades que a elaboração do método pedagógico da pedagogia histórico-crítica se deu em conformidade com o Método da Economia Política de Marx (2008a), contido em seu livro Contribuição à crítica da economia política, texto que também pode ser encontrado na obra traduzida em português pelo professor Mario Duayer, intitulada Grundrisse: Manuscritos econômicos de 1857-1858: Esboços da critica da economia politica (MARX, 2011). Conforme já evidenciado por Saviani (2008a), reportando-se ao método pedagógico: "Nele explicita-se o movimento do conhecimento como a passagem do empírico ao concreto, pela mediação do abstrato. Ou a passagem da síncrese à síntese, pela mediação da análise" (SAVIANI, 2008a, p. 142).

Tendo-se em vista essas consideraçóes iniciais, pretendemos neste texto realizar uma discussão acerca do método pedagógico da pedagogia histórico- 
crítica, a partir do encaminhamento de possíveis saídas teóricas para os seguintes questionamentos: o que significa transmissão de conhecimento para a pedagogia histórico-crítica? Como se configura o "bom ensino" na educação escolar? Qual é, na realidade, o significado da defesa de o conhecimento escolar ser transmitido nas suas formas mais desenvolvidas? Qual o critério de desenvolvimento empregado por essa teoria pedagógica? Sendo assim, procuraremos contribuir com as respostas a essas questóes ao longo deste artigo.

Para tanto, precisamos compreender a relação já anunciada entre o método de Marx (2011) e o método pedagógico de Saviani (2008a), de modo a realizar uma proposição pedagógica histórico-crítica. Sustentar uma prática educativa pautada pelo materialismo histórico-dialético pressupóe movimento, historicidade, contradição e totalidade. Daí que a pedagogia histórico-crítica não possa ser didatizada em passos estanques, que se submetem à lógica formal $\mathrm{e}$ assim perdem a essência, a dinâmica dessa teoria pedagógica, transformando-se em algo esvaziado, quase um receituário, que em lugar de oportunizar o avanço da escola, só a reforça como farsa.

\section{O método pedagógico em questão}

Compreender o método em Marx (2011) é algo que requer um esforço muito grande por parte daqueles que se dispóe a fazê-lo. Há pouquíssimas páginas no conjunto de sua obra de fato dedicadas à questáo do método. Isto porque ele jamais se preocupou em escrever regras metodológicas a serem aplicadas em um contexto social independente do objeto do conhecimento.

É exatamente ao longo do processo de elaboração de toda sua teoria social que Marx - e com ele Engels - foi elaborando e determinando o método adequado para compreensão da realidade social. Como salienta Netto (2011), tal método resulta de mais de 15 anos de pesquisas e, somente depois de demoradas e rigorosas investigaçóes é que foi possível a estes autores elaborar com precisão os elementos centrais do método tal qual sistematizado por Marx na famosa "Introdução" redigida em 1857.

As bases do método que viabilizou toda a análise contida n'O Capital (MARX, 2008b), bem como, a fundação de sua teoria social, não podem ser compreendidas como um conjunto de regras, tampouco, um rol de definiçôes as quais servem para orientar a busca pelo conhecimento. Conforme Netto (2011, p. 52): 
[...] para Marx, o método não é um conjunto de regras formais que se "aplicam" a um objeto que foi recortado para uma investigaçáo determinada nem, menos ainda, um conjunto de regras que o sujeito que pesquisa escolhe, conforme a sua vontade, para "enquadrar" o seu objeto de investigação.

É evidente que o conjunto da obra elaborada por Marx e Engels teve como objeto central de análise a sociedade burguesa. Tais autores se defrontaram por mais de quarenta anos com este objeto de estudo, explicitando as formas de captá-lo na realidade social, explicá-lo, expor suas contradiçóes e apontar as possibilidades de sua superaçáo. É o que tais autores nos deixaram enquanto legado teórico: a gênese, o desenvolvimento, a consolidação, as condiçóes de crise e a superaçáo da ordem burguesa, fundada no modo de produção capitalista.

Tal percurso teórico-metodológico é inaugurado por Marx em 1843 e 1844, quando se confronta polemicamente com a filosofia de Hegel - sob a influência do materialismo de Feuerbach - tendo como ponto de partida a tentativa de compreender uma contradiçấo material a qual ele mesmo experimentara: o decreto assinado por Frederico Guilherme IV declarando furto de lenha aos camponeses que coletassem madeira nas fazendas e florestas prussianas (o que antes era tratado como um direito consuetudinário).

Este dado nos parece algo de extrema importância, senão vejamos: nosso jovem Marx pretendia compreender teoricamente algo que se apresentava a ele como um problema da prática social. Tal questáo não se caracterizava como uma reflexão pela mera reflexão, mas sim, a busca de colocar em movimento o pensamento teórico para a compreensão da prática social ${ }^{1}$.

Assim, já no início do percurso de toda sua atividade teórica, Marx nos deixa algo assinalado: o pensamento, por meio da atividade teórica, deve reproduzir idealmente o objeto ou o fenômeno da prática social. Este é o significado da sua teoria: a reprodução ideal do movimento real.

Marx e Engels (2007) buscaram reproduzir idealmente - no plano das ideias, no plano do pensamento - a estrutura e a dinâmica do objeto com o qual se defrontaram por mais de quarenta anos: a lógica do capital. Com efeito,

[...] Marx não nos apresentou o que "pensava" sobre o capital, a partir de um sistema de categorias previamente elaboradas e ordenadas conforme operaçôes intelectivas: 
ele (nos) descobriu a estrutura e a dinâmica reais do capital; náo lhe "atribuiu" ou "imputou" uma lógica: extraiu da efetividade do movimento do capital a sua (própria, imanente) lógica - numa palavra, deu-nos a teoria do capital. (NETTO, 2011, p. 52-53, grifo do autor).

Reproduzir no plano do pensamento o movimento real do objeto é o que Marx e Engels (2007) entendiam por teoria. O conhecimento teórico é o conhecimento do objeto, o conhecimento do seu movimento real reproduzido em pensamento. Portanto, para os autores:

Teoria é a reproduçáo ideal do movimento do real. Isto significa uma concepçáo ontológica de teoria, ou seja, não há nada que se passe na cabeça que não se tenha passado antes na própria realidade, assim "reprodução ideal" significa a "re-construção" no plano das ideias de algo que se passa, anteriormente, na realidade. Porém, essa mesma realidade é compreendida como processualidade, como movimento, enfim, como um constante vir-a-ser que carrega em si elementos de continuidade e de superação. A investigação sobre o social não é, portanto, uma fotografia, um espelhamento do real. (HUNGARO, 2008, p. 21-22).

Com efeito, o significado do conhecimento teórico em Marx foi intencionalmente incorporado pelo professor Dermeval Saviani (2008b, p.263) na sistematização do método pedagógico da pedagogia histórico-crítica. Esta teoria entende que é função da educaçáo escolar elevar o pensamento do aluno da síncrese ("a visão caótica do todo") à síntese ("uma rica totalidade de determinações e relações numerosas") pela mediação da análise ("as abstrações e determinaçóes simples"), partindo da formulaçáo do método em Marx.

A mediação da abstração ocorre no campo da educação escolar a partir do desenvolvimento do pensamento teórico dos alunos. Essa é a defesa que a pedagogia histórico-crítica incessantemente busca fazer: a educação escolar deve propiciar processos de abstraçáo do pensamento a partir do desenvolvimento da teoria e dos conteúdos de ensino.

A elevação do pensamento empírico ao pensamento teórico - este superando aquele por incorporação, portanto, prescindindo daquele como parte 
de um processo mais amplo e complexo de apreensão do pensamento - não ocorre de maneira naturalmente espontânea, mas sim, pressupóe a exigência de situaçóes planejadas e organizadas, tornando ímpar o processo de ensino escolar. Conforme nos aponta a professora Lígia Márcia Martins (2011, p. 54, grifo da autora):

[...] a posse, por parte de cada indivíduo particular, dos atributos humanos, no que incluem as plenas possibilidades do pensamento, é processo socialmente dependente. Para isso ocorrer, contudo, demanda que forças objetivas operem a esse favor. Tal como postulado com a pedagogia histórico-crítica, operar nessa direçáo é função precípua da educação escolar, a quem compete a tarefa de ensinar, isto é, promover a socializaçáo dos conhecimentos representativos das máximas conquistas científicas e culturais da humanidade, por meio da prática pedagógica, tornando a realidade inteligível.

A partir disso se compreende as fortes afinidades da pedagogia históricocrítica com a psicologia histórico-cultural, sobretudo, considerando-se seus fundamentos epistemológicos de base marxista.

Conforme postulado pela Escola de Vigotski, as funçóes psicológicas superiores - as quais são próprias dos seres humanos - só se desenvolvem no exercício do seu funcionamento, ou seja, não são passíveis de serem desenvolvidas à luz de atividades livres, que não exijam e possibilitem seu desenvolvimento.

Assim, a pedagogia histórico-crítica, bem como a psicologia históricocultural, amparadas no materialismo histórico-dialético, incorporarão a tese de que cabe à escola e ao trabalho educativo escolar a tarefa do desenvolvimento destas funções psicológicas superiores. Com efeito:

Tais ações exigem, necessariamente, um tipo de pensamento que promova a superação da empiria fetichizada, das aparências - sejam elas falsas ou verdadeiras -, instrumentalizando os indivíduos para a atividade consciente, para a transformaçáo das circunstâncias e de si mesmos. É com essa tarefa que entendemos a educação escolar verdadeiramente emancipadora, e a serviço dela colocam-se tanto 
a pedagogia histórico-crítica quanto a psicologia histórico-cultural. (MARTINS, 2011, p. 56-57).

Reproduzir o movimento do objeto em pensamento - a busca do conhecimento teórico - não significa, portanto, uma reflexão mecânica, um espelhamento ou fotocópia da realidade na consciência. Se assim fosse o papel do indivíduo na busca pelo conhecimento seria meramente passivo. Bastaria mirar o objeto, ou, valendo-se de uma expressão tipicamente pós-moderna, lançar um olhar.

O processo de conhecimento para Marx e Engels (2007) não se dá por intermédio do imediatismo do pensamento. O conhecimento do real náo pode se limitar àquilo que é imediatamente dado, pensado ou sentido. Se o pensamento se limita a isso, ele se póe no nível da obviedade, restringe-se a captar o evidente.

A questão que se coloca quanto ao problema da constatação do óbvio é a de que este nível de apreensão da realidade não captura sua estrutura e dinâmica, náo propicia o conhecimento da essência do real ou do objeto estudado. E, como se sabe, a distinção entre aparência e essência é fundamental para a lógica dialética:

É preciso, portanto, ultrapassar os limites destas manifestaçôes mais imediatas para conhecer quais são suas raízes processuais, não imediatamente perceptíveis, que formam a totalidade onde tais manifestaçóes são produzidas. Dizendo de outra forma: é preciso compreender o processo ontológico da realidade humana e de como esse processo tem se efetivado, historicamente, dentro das relaçóes sociais de produção. (OLIVEIRA, 2005, p. 9).

A aparência fenomênica, imediata e empírica da realidade é importante e não pode ser descartada, visto que ela é o ponto de partida do processo do conhecimento - portanto, necessariamente onde se inicia o conhecimento. Não obstante, deve-se, partindo dessa aparência, alcançar a essência do objeto de estudo, capturar sua estrutura e dinâmica, bem como, suas múltiplas determinaçóes. Com efeito, Marx (2011) não deixa dúvidas quanto à capacidade intelectiva da abstração como aquela necessária para se realizar o procedimento 
analítico de ultrapassagem da aparência imediata da realidade. É ela, a abstração, que permite extrair um elemento da realidade, isolá-lo e examiná-lo nas suas particularidades, extraindo deste elemento suas múltiplas determinaçóes por meio da saturação da análise. Vejamos o que o autor nos afirma:

Parece ser correto começarmos pelo real e pelo concreto, pelo pressuposto efetivo, e, portanto, no caso da economia, por exemplo, começarmos pela populaçáo, que é o fundamento e o sujeito do ato social de produçáo como um todo. Considerado de maneira mais rigorosa, entretanto, isso se mostra falso. A população é uma abstração quando deixo de fora, por exemplo, as classes das quais é constituída. Essas classes, por sua vez, são uma palavra vazia se desconheço os elementos nos quais se baseiam. [...] Por isto, se eu começasse pela população, esta seria uma representaçáo caótica do todo e, por meio de uma determinação mais precisa, chegaria analiticamente a conceitos cada vez mais simples; do concreto representado [chegaria] a conceitos abstratos [Abstrakta] cada vez mais finos, até que tivesse chegado às determinaçōes mais simples. Daí teria de dar início à viagem de retorno até que finalmente chegasse de novo à população, mas desta vez não como a representação caótica de um todo, mas como uma rica totalidade de muitas determinaçôes e relações. (MARX, 2011, p. 54).

A abstração é um recurso decisivo do pensamento a qual possibilita aquilo que Marx (2011) denominou de as determinaçôes as mais simples do objeto, determinaçóes estas que se caracterizam pelos traços constitutivos pertinentes ao objeto. Após este alcance das determinaçóes as mais simples, é que o autor aponta a necessidade de se fazer o caminho de volta, ou seja, retornar a realidade concreta, porém, não mais como uma representação caótica de um todo, mas uma rica totalidade de determinaçóes.

Essa viagem de modo inverso é, para Marx (2011), o concreto pensado, aquele em que o abstrato elevou-se ao concreto, o ponto de chegada que é, ao mesmo tempo, o verdadeiro ponto de partida.

Como se sabe, a prática social é questão central da pedagogia históricocrítica, notadamente, considerado-a ponto de partida e ponto de chegada da 
prática educativa. Cabe salientar que essa relação entre o ponto de partida e o ponto de chegada reflete o movimento dialético inerente ao método marxiano, presente em todo o encaminhamento da proposta pedagógica e que exige do planejamento de ensino a pontuação dos conteúdos escolares que possibilitem aos alunos a visão de totalidade dos fenômenos da prática social, analisados em sua história e contradiçôes.

Dessa forma, na proposição da prática social como ponto de partida da prática educativa, o que está se destacando é:

[...] antes de tudo, a natureza histórico-social da educaçāo escolar. Seu cunho é filosófico e não procedimental, isto é, o que está em questão, a rigor, é o trabalho pedagógico como uma das formas de expressão da prática social, na base da qual residem as relaçôes sociais de produção que geram, para além de "coisas", a própria subjetividade humana como intersubjetividade (SAVIANI, 2004). [...] Assim, não entendemos que o ponto de partida seja representado por algum "problema" que se desprenda da realidade circundante e imediata e se coloque como conteúdo escolar, muito menos por aquilo que os alunos já sabem - seus conhecimentos experienciais - e que coabitam seu nível de desenvolvimento real. Pensamos que, em tela, está a necessidade de se reconhecer tanto o professor quanto o aluno em sua concretude, isto é, como sínteses de múltiplas determinaçôes e a prática pedagógica como um tipo de relação que pressupóe o homem unido a outro homem, em um processo mediado pelas apropriaçóes e objetivaçôes que lhes são disponibilizadas. (MARTINS, 2013, p. 290).

Ao tratar da relação educação e transformação social, essa teoria pedagógica concebe a educação como uma atividade mediadora no interior da prática social global. É essa atividade que viabiliza que os indivíduos ultrapassem o pensamento imediato pautado na empiria fenomênica da prática social e, por meio da abstração - vale afirmar, da análise e da atividade teórica - desenvolvam formas de pensamento que captem a mesma prática social, não mais como uma representação caótica do todo, mas como uma rica totalidade de relaçóes sociais, operando por processos de síntese das múltiplas determinaçóes da prática social. 
No sentido de enfrentar os problemas que a prática social, sobretudo a realidade educacional brasileira nos impõe, a pedagogia histórico-crítica busca articular dialeticamente teoria e prática, tendo sempre como guia a tese de número 2 de Marx e Engels (2007) sobre Feuerbach ${ }^{2}$. Nesse sentido, enquanto teoria pedagógica, ela recorre a autores clássicos - sobretudo do campo marxista - não para apenas chegar à interpretação supostamente correta desses textos, mas para poder melhor compreender a realidade concreta e responder aos problemas enfrentados.

É por isso que a pedagogia histórico-crítica supera - por incorporação tanto a pedagogia tradicional quanto a pedagogia nova. De certo, a pedagogia tradicional buscou articular um conjunto de questôes acerca da problemática do ensino e, em decorrência disso, acabou por acentuar a teoria sobre a prática, na busca de respostas à pergunta "como ensinar". Assim, ela se constitui como uma "teoria do ensino", subordinando e, no limite, dissolvendo a prática à teoria (SAVIANI, 2008b).

Em contraposição, a pedagogia nova deslocou as questóes acerca da educação para a problemática da aprendizagem, subordinando a teoria à prática, sobretudo dissolvendo aquela nesta. Ao procurar as respostas relativas à pergunta "como aprender", chegou-se a generalização do lema "aprender a aprender" (SAVIANI, 2008b). Sendo assim,

A oposição entre as duas tendências pedagógicas decorre das ênfases distintas com que cada uma delas lida com os vários elementos integrantes do processo pedagógico. A primeira tendência, a tradicional, pondo a ênfase na teoria, reforça o papel do professor, entendido como aquele que, detendo os conhecimentos elaborados, portanto, o saber teoricamente fundamentado, tem a responsabilidade de ensinar aos alunos mediante procedimentos adequados que configuram os métodos de ensino. A segunda tendência, a renovadora, pondo a ênfase na prática, reforça o papel do aluno, entendido como aquele que só pode aprender na atividade prática, isto é, na medida em que [...] realiza, com o auxílio do professor, os passos de sua própria educação, que configuram os métodos de aprendizagem mediante o qual ele, aluno, constrói os próprios conhecimentos. (SAVIANI, 2008b, p. 259). 
Assim, Saviani (2008b) identifica que as duas correntes pedagógicas anteriormente citadas acabam por cair num dilema que, devido ao caminho lógico da busca da resposta, não conseguem superá-lo. Ao tratar da questão da teoria e prática por intermédio da construção do pensamento inscrito na lógica formal, acabam por operar por exclusão, desconsiderando duas conclusões contraditórias igualmente possíveis logicamente.

Os formuladores da pedagogia histórico-crítica, ao buscarem pensar não só as contradições, mas por contradição - haja vista a exigência do método de Marx -, entendem, pois, que teoria e prática são polos opostos que se incluem, podendo ser considerados como uma unidade, uma unidade de contrários. Assim,

Consideremos o problema da relação entre teoria e prática tendo presente este entendimento dialético. Teoria e prática são aspectos distintos e fundamentais da experiência humana. Nessa condição podem, e devem, ser consideradas na especificidade que as diferencia, uma da outra. Mas, ainda que distintos, esses aspectos são inseparáveis, definindo-se e caracterizando-se sempre um em relação ao outro. Assim, a prática é a razão de ser da teoria, o que significa que a teoria só se constituiu e se desenvolveu em funçáo da prática que opera, ao mesmo tempo, como seu fundamento, finalidade e critério de verdade. A teoria depende, pois, radicalmente da prática. Os problemas de que ela trata sáo postos pela prática e ela só faz sentido enquanto é acionada pelo homem como tentativa de resolver os problemas postos pela prática. Cabe a ela esclarecer a prática, tornando-a coerente, consistente, consequente e eficaz. Portanto, a prática igualmente depende da teoria, já que sua consistência é determinada pela teoria. Assim, sem a teoria, a prática resulta cega, tateante, perdendo sua característica específica de atividade humana. (SAVIANI, 2008b, p. 261-262).

Como se vê, a formulação da teoria pedagógica histórico-crítica se propôs a superar a oposiçáo excludente entre teoria e prática, articulando-as como uma unidade que se contrapóem entre si, dinamizando e colocando em movimento a prática pedagógica. Para tanto, foi preciso superar o quadro da lógica formal: 
Enquanto tal, a lógica formal incide sobre o momento analítico, portanto, abstrato, quando o pensamento busca se apropriar da realidade concreta que, sendo síntese de múltiplas determinaçóes, é unidade da diversidade, portanto, algo complexo que articula elementos opostos. Para apreender o concreto nós precisamos identificar os seus elementos e, para isto, nós os destacamos, os isolamos, separamos uns dos outros pelo processo de abstraçáo, procedimento este que é denominado de análise. Uma vez feito isto, para apreender o concreto nós precisamos fazer o caminho inverso, isto é, recompor os elementos identificados rearticulando-os no todo de que fazem parte de modo a perceber suas relaçóes. Com isto nós passamos de uma visão confusa, caótica, sincrética do fenômeno estudado chegando, pela mediação da análise, da abstração, a uma visão sintética, articulada, concreta. (SAVIANI, 2008b, p. 261).

Ressalta-se, mais uma vez, a importância do método de Marx incorporado por Saviani (2008b) como um método pedagógico para se pensar concretamente a educação inserida na prática social. Com efeito, pode-se considerar a pedagogia histórico-crítica como uma pedagogia concreta.

Para esta teoria pedagógica, os indivíduos são seres humanos concretos, portanto, síntese de múltiplas relaçóes sociais. Não são indivíduos abstratos, os quais por intermédio da educação se busca atingir uma essência humana abstrata, como considera a pedagogia tradicional, tampouco indivíduos empíricos e singulares os quais se diferenciam uns dos outros por suas disposiçôes internas e naturais, como pensa a pedagogia nova. Portanto,

[...] o movimento que vai das observações empíricas ("o todo configurado na intuição") ao concreto ("uma rica totalidade de determinaçôes e de relaçóes numerosas") pela mediação do abstrato ("a análise, os conceitos e as determinaçóes mais simples”) constitui uma orientaçáo segura tanto para o processo de descoberta de novos conhecimentos (o método científico) como para o processo de ensino (o método pedagógico). É a partir daí que podemos chegar a uma pedagogia concreta como via de superação tanto da pedagogia tradicional como da pedagogia moderna. (SAVIANI, 2012, p. 78-79, grifo do autor). 
Trata-se, pois, "[...] de compreender a educação como um elemento inserido no movimento dialético de transformação da realidade, abrangendo desde as formas de produção das relaçôes sociais até a inserção da educação nesse movimento" (BATISTA; LIMA, 2012, p. 27). A passagem da síncrese à síntese pela mediação do abstrato se configura, pedagogicamente, na transformação da prática social - enquanto ponto de partida e ponto de chegada - por intermédio da problematização desta prática social, pela instrumentalização (para além do pensamento empírico) e pela catarse (enquanto síntese de desenvolvimento do aluno e, consequentemente, da possibilidade de alteraçáo da prática social). Esta é a riqueza, em nosso entendimento, do método pedagógico da pedagogia histórico-crítica:

[...] isso significa que a educação é entendida como mediaçáo no seio da prática social global. A prática social póe-se, portanto, como o ponto de partida e o ponto de chegada da prática educativa. Daí decorre um método pedagógico que parte da prática social em que professor e aluno se encontram igualmente inseridos, ocupando, porém, posiçóes distintas, condição para que travem uma relação fecunda na compreensão e no encaminhamento da solução dos problemas postos pela prática social. Aos momentos intermediários do método, cabe identificar as questôes suscitadas pela prática social (problematização), dispor os instrumentos teóricos e práticos para a sua compreensão e solução (instrumentalização) e viabilizar sua incorporação como elementos integrantes da própria vida dos alunos (catarse). (SAVIANI, 2011, p. 422).

Ao professor cabe a tarefa importantíssima de transmitir o conhecimento socialmente existente ao aluno, para que este possa apreender a realidade social, também, como síntese de múltiplas relações (totalidade), atuando conscientemente e portando os instrumentos necessários para a transformação da realidade.

O conhecimento socialmente existente e acumulado historicamente é de extrema importância e corresponde diretamente com os interesses do aluno concreto. Prescindir deste conhecimento é impossibilitar o indivíduo de pensar conscientemente a realidade social e desarmá-lo para atuar criticamente nesta mesma realidade. Quão distante nos parece a pedagogia histórico-crítica das 
ditas "teorias tradicionais do currículo" e quão simplista nos parece o argumento de que defender a transmissão de conhecimento seja compartilhar de uma "educação bancária".

No trato com os indivíduos concebidos enquanto sínteses de relações sociais, o saber sistematizado é uma exigência da sociedade: “[...] ele está situado numa sociedade que póe a exigência deste tipo de conhecimento. $\mathrm{E}$ é, sem dúvida, tarefa precípua da educação viabilizar o acesso a esse tipo de conhecimento" (SAVIANI, 2008a, p. 144). Nesse sentido, Saviani (2008a, p. 143, grifo nosso) afirma que:

Se a educação é mediação no seio da prática social global, e se a humanidade se desenvolve historicamente, isso significa que uma determinada geração herda da anterior um modo de produção com os respectivos meios de produção e relaçôes de produção. E a nova geraçáo, por sua vez, impóe-se a tarefa de desenvolver e transformar as relações herdadas das gerações anteriores. Nesse sentido, ela é determinada pelas geraçôes anteriores e depende delas. Mas é uma determinação que não anula a sua iniciativa histórica, que se expressa justamente pelo desenvolvimento e pelas transformaçôes que ela opera sobre a base das produçôes anteriores. A educação, na medida em que é uma mediação no seio da prática social global, cabe possibilitar que as novas geraçôes incorporem os elementos herdados de modo que se tornem agentes ativos no processo de desenvolvimento e transformação das relaçôes sociais.

Por isso é que a pedagogia histórico-crítica se posiciona veementemente em defesa da escola e da assimilaçáo dos conteúdos científicos, artísticos e filosóficos por parte dos alunos, afinal, "[...] o ser humano para formar-se enquanto sujeito transformador da realidade social da qual ele é parte, precisa relacionar-se com essa realidade pela mediação da apropriação do conhecimento produzido" (OLIVEIRA, 1996, p. 63).

Conhecer a realidade e compreendê-la criticamente não é um processo imediato do desenvolvimento humano, tampouco uma iluminação súbita da consciência ou uma graça divina. "O ler uma realidade de forma crítica [...] passa pela mediação da apropriação do conhecimento, sem a qual a leitura 
crítica do concreto é impossível. É a apropriação do conhecimento através da educação escolar" (OLIVEIRA, 1996, p. 63-64).

Tratar dos conteúdos em articulação com as formas de sua assimilação por intermédio da lógica dialética é uma constante dessa teoria pedagógica, empenhando-se em fazer essa articulação - visto que a separação entre forma e conteúdo é própria da lógica formal. Retomemos as palavras de Saviani (2008a, p. 144):

Quando se insiste na importância dos conteúdos, o que se está frisando aí é a necessidade de trabalhar a educação em concreto e não de forma abstrata. Com efeito, a lógica formal é a lógica das formas e, como o próprio nome está dizendo, é abstrata. A lógica dialética é uma lógica concreta. É a lógica dos conteúdos. Não, porém, dos conteúdos informes, mas dos conteúdos em sua articulação com as formas.

\section{Continuemos com o autor:}

[...] a questão pedagógica, em sua essência, é a questão das formas. Estas, porém, nunca podem ser consideradas em si mesmas. E a diferenciação sempre se dará pelo conteúdo. Se for feita a abstração dos conteúdos, fica-se com a pura forma. Aí ocorre a indiferenciaçáo. É nesse sentido que os conteúdos são importantes. Tratar as formas em concreto e não em abstrato é tratá-las pela via dos conteúdos. (SAVIANI, 2008a, p. 145).

Trata-se, pois, de uma pedagogia transformadora e revolucionária que faz crítica à sociedade capitalista, proclamando a superaçáo desta sociedade e a construção de um novo homem, pelo estabelecimento de relações sociais plenas de conteúdo.

Assim, claramente a pedagogia histórico-crítica advoga a superação da sociedade de classes, a qual priva os indivíduos do seu pleno desenvolvimento e, ao mesmo tempo, defende uma educaçáo escolar que dá centralidade à transmissão e à apropriação dos conteúdos clássicos integrantes da cultura universal humana, incorporando a concepçáo marxista de comunismo, que defende "[...] uma sociedade na qual as relaçóes humanas e a vida humana 
são plenas de conteúdo, em oposição ao caráter unilateral, abstrato e vazio das relações humanas na sociedade capitalista" (DUARTE, 2011, p. 18). Logo,

Quando a pedagogia histórico-crítica coloca em primeiro plano a socialização pela escola das formas mais desenvolvidas do conhecimento até aqui produzido pela humanidade, seu fundamento é justamente o de que a vida humana na sociedade comunista é uma vida plena de conteúdo da mesma forma que as relaçóes entre os indivíduos na sociedade comunista se tornam plenas de conteúdo. [...] nessa sociedade as relações entre os indivíduos se mostram plenamente humanizadas. (DUARTE, 2011, p. 19-20).

A prática pedagógica na educação escolar deve, portanto, encadear o movimento do pensamento de forma correspondente ao movimento da realidade objetiva. Conforme explicitado no método da economia política, o lógico - as leis do pensamento - necessita corresponder com o histórico, as leis dos fenômenos do mundo objetivo.

Dessa forma, o objeto de estudo (o conteúdo de ensino) possui uma existência objetiva. Ele náo depende do professor para existir, tampouco da consciência do aluno em processo de escolarizaçáo. Desta feita, o método da pedagogia histórico-crítica implica uma dada posição ou perspectiva do ato de ensinar: "[...] aquela em que se pốe o sujeito para, na sua relação com o objeto, extrair dele as suas múltiplas determinaçôes" (NETTO, 2011, p. 53). Essa ideia articula-se ao que Saviani (2009) denomina "problematizaçấo".

Ao referir-se à necessidade de estabelecer a relação escola-sociedade, ao assinalar que o que desconhecemos (individualmente) ou simples perguntas não constituem o que seja, de fato, um problema (no sentido filosófico) e ao sustentar o que é problema, como aquilo que necessitamos conhecer em essência, de forma articulada e coesa, porque se constitui como "[...] um obstáculo que é necessário transpor, uma dificuldade que precisa ser superada, uma dúvida que não pode deixar de ser dissipada" (SAVIANI, 2000, p. 14), Saviani (2009) sinaliza a importância da seleção dos conteúdos - que sejam clássicos -, porque verdadeiramente contribuem para a transformação da prática concreta. Ademais, como destaca Martins (2013, p. 291), a problematização: 
[...] tem um caráter bem amplo e não guarda correspondência direta com procedimentos que instiguem ou problematizem aquilo que venha a ser ensinado pelo professor aos seus alunos. Trata-se, outrossim, da identificação dos problemas impostos à prática educativa, ao trabalho do professor, à vista dos encaminhamentos de suas possíveis resoluçóes. [...] Portanto, sob nosso entendimento, o segundo momento aponta na direção das condiçôes requeridas ao trabalho pedagógico, à prática social docente. Aspectos infraestruturais, salariais, domínios teórico-técnicos, estrutura organizativa da escola e, sobretudo, a qualidade da formação docente, são algumas questôes a serem problematizadas.

Se a problematização tem sentido como questóes da prática social que precisam ser resolvidas, e se na escola tomamos a transmissão de conhecimentos como premissa da transformação da prática social, são as leis do ser do objeto de estudo, ou seja, do conteúdo de ensino - em suas formas ontológicas - transformado em leis do pensamento, que se convertem em método de ensino. Náo obstante, para transformar as leis da realidade objetiva em leis do pensamento é necessário torná-las formas lógicas. E não é qualquer lógica que possibilita tal percurso do pensamento. Para Oliveira (1996, p. 59, grifo nosso), "[...] é preciso ultrapassar os quadros lógico-formais do pensamento e buscar, numa concepção dinâmica de realidade, uma lógica e uma metodologia que dêem conta do movimento real na sua contraditoriedade".

A lógica formal, embora tenha uma função específica e importante no processo de conhecimento da realidade, na medida em que busca identificar, caracterizar e classificar os elementos por si mesmos e em suas especificidades, mostra-se insuficiente para apreender a realidade em sua dinamicidade, processualidade e em movimento (OLIVEIRA, 2005).

Em que pese que a lógica formal seja necessária para identificar cada elemento da realidade em suas características específicas e classificá-los conforme parâmetros e princípios inerentes do processo de conhecimento, ela não possibilita captar as relações e as mediações desses múltiplos elementos do real.

Seu critério lógico de identificação, organização, catalogação e classificação de cada complexo constitutivo da realidade é uma organização meramente lógico-formal dos elementos do real, elementos estes considerados estáticos, 
sem movimento. É por isso que Saviani (2008b) considera a validade da lógica formal, porém circunscrita à lógica das formas.

Oliveira (2005, p. 14) sintetiza a necessidade da lógica dialética tomada enquanto forma de se elevar o concreto no pensamento:

Para captar o movimento da realidade, na concepção metodológica marxiana, torna-se necessário utilizar-se a lógica inerente ao movimento da própria realidade que é dinâmica, não só no sentido de avançar numa determinada direçáo, mas através da intensa reciprocidade dos elementos que a constituem. É a lógica dialética. As leis da lógica dialética são exatamente as leis que dirigem o movimento objetivo da realidade transformadas em leis do pensamento e que se nos apresentam através de conceitos de máxima generalidade.

Se a prática social é tomada como ponto de partida e de chegada da prática pedagógica e se a problematizaçâo identifica-se com as necessidades postas pela prática social, cabe agora explicitar a instrumentalização como central no processo de ensino.

A instrumentalização refere-se aos conteúdos a serem disponibilizados aos alunos e a forma como são abordados para que efetivamente se tornem instrumentos da prática social. Com efeito, a pedagogia histórico-crítica vem lutando para que se tenha, ainda nesta forma de sociedade, a máxima efetivação das possibilidades de ensino e aprendizagem dos conteúdos escolares.

Tomando como referência e elemento central a questáo do saber objetivo, a teoria pedagógica histórico-crítica parte em defesa da socialização do conhecimento e do trabalho organizado e sistematizado dos professores como forma de produzir, direta e intencionalmente, em cada aluno singular, o domínio dos conhecimentos plenamente desenvolvidos pela humanidade ao longo da história. Isso porque:

[...] a escola tem a ver com o saber universal. Portanto, se o saber escolar, em nossa sociedade, é dominado pela burguesia, nem por isso cabe concluir que ele é intrinsecamente burguês. Daí a conclusão: esse saber, que, de si, não é burguês, serve, no entanto, aos interesses burgueses, uma vez que a burguesia dele se apropria, 
coloca-o a seu serviço e o sonega das classes trabalhadoras. Portanto, é fundamental a luta por essa sonegação, uma vez que é pela apropriação do saber escolar por parte dos trabalhadores que serão retirados desse saber seus caracteres burgueses e se lhe imprimirão os caracteres proletários. (SAVIANI, 2008a, p. 55).

Como se vê, o saber escolar é para esta teoria pedagógica a organização sequencial e gradativa do saber objetivo e universal disponível e acumulado socialmente, o qual foi - e é - construído historicamente, conforme determinada etapa da humanidade. Para efeito de cumprimento de sua função social, cabe ao processo de escolarização a transmissão e a assimilação deste conhecimento objetivo convertido em saber escolar.

Conforme indicado por Saviani (1984), não se trata de um momento de cunho tecnicista, mas sim que visa transmitir às novas geraçôes o saber historicamente sistematizado. Entendemos que esse passo radica na relação interpessoal professor-aluno mediada pelos conhecimentos a serem transmitidos e que possibilitem à educação escolar desempenhar efetivamente sua função social. (MARTINS, 2013, p. 292).

Com efeito, o esvaziamento dos conteúdos nas escolas é característica da estratégia de dominação burguesa. N'O Capital, Marx (2008b) descreve o processo histórico pelo qual, conforme o desenvolvimento dos processos de trabalho no período por ele intitulado de acumulação primitiva, o qual corresponde à passagem do artesanato à grande indústria, percorrendo a cooperação simples e a manufatura, os trabalhadores váo sendo gradativamente destituídos dos conhecimentos e dos saberes dos processos produtivos.

Exatamente por isso, já no início da formulação da teoria pedagógica, que Saviani (2009) a coloca na perspectiva da defesa intransigente pelo aprimoramento do ensino destinado às classes populares. $\mathrm{O}$ autor afirma que:

Essa defesa implica a prioridade de conteúdo. Os conteúdos são fundamentais e sem conteúdos relevantes, conteúdos significativos, a aprendizagem deixa de existir, ela transforma-se num arremedo, ela transforma-se numa 
farsa. Parece-me, pois, fundamental que se entenda isso e que, no interior da escola, nós atuemos segundo esta máxima: a prioridade de conteúdos, que é a única forma de lutar contra a farsa do ensino. [...] Se os membros das camadas populares não dominam os conteúdos culturais, eles não podem fazer valer seus interesses, porque ficam desarmados contra os dominadores, que se servem exatamente desses conteúdos culturais para legitimar e consolidar a sua dominação. [...] o dominado náo se liberta se ele não vier a dominar aquilo que os dominantes dominam. Então, dominar o que os dominantes dominam é condição de libertaçáo. (SAVIANI, 2009, p. 50-51).

A prioridade do conteúdo no trabalho educativo, tal qual expresso anteriormente, deve possibilitar a concretização do "bom ensino", ou seja, materializar no âmbito do ensino escolar aquilo que Marx (2011) nos legou enquanto método: reproduzir os traços essenciais do objeto de estudo.

Afirmando de outra maneira, cabe à educação escolar, no processo de transmissão do conteúdo de ensino, procurar reproduzir nas aulas as determinaçôes do objeto, notadamente fazer com que os alunos reproduzam em pensamento os traços constitutivos do conteúdo de ensino. Este ensino será tão mais verdadeiramente um "bom ensino" quanto mais saturado o pensamento do aluno estiver com as determinaçôes e as mediaçôes reais do conteúdo.

Desse modo, há que se reproduzir o objeto de ensino nas suas formas mais desenvolvidas, evidenciando-se a lógica de sua estrutura e dinâmica mais atual, mais desenvolvida. Este é o ponto de partida de todo o objeto de ensino na educação escolar. Cabe a cada uma das matérias de ensino, seja a Filosofia, Educação Artística, Educação Física, História, Matemática, Geografia, dentre outras, identificar as formas mais desenvolvidas de seus objetos de ensino ${ }^{3}$ para que, partindo dele, ainda que como uma representação caótica do todo, se realize a análise do objeto em suas formas mais simples, ou seja, proceda-se a análise histórica do objeto, reproduzindo sua gênese e seu desenvolvimento por meio da abstração, em busca da compreensão das fases anteriores do processo histórico do objeto.

A análise das determinaçôes mais simples do objeto de estudo por meio da abstração (uma atividade teórica, um trabalho intelectivo) permite à educação 
escolar evidenciar as formas categorias do objeto, as formas do modo de ser do conteúdo de ensino. E tal qual afirmou Marx, as categorias exprimem as determinaçóes da existência, sendo, portanto, categorias ontológicas, visto que pertencem à ordem do ser.

É esta análise abstrativa do conteúdo, reconhecendo suas determinações mais simples, sobretudo sua riqueza categorial, que aprofunda a compreensão da forma mais desenvolvida do objeto de estudo, possibilitando a reprodução do concreto em pensamento de forma ainda mais rica. Realizando o percurso de volta, como chamou Marx, cabe ao pensamento agora ascender deste trabalho analítico abstrativo à complexidade do conjunto do objeto de estudo o qual se apresentou, de forma inicial, de maneira caótica, mas que agora se apresenta como síntese de múltiplas determinaçóes.Portanto,

O trabalho analítico com as categorias mais simples e abstratas seguirá agora o percurso do progressivo enriquecimento da teoria interpretativa da realidade, até atingir novamente o todo que foi o ponto de partida, só que esse todo já não mais se apresenta ao pensamento como uma representação caótica, mas como "uma rica totalidade de determinaçóes e relaçôes diversas". O concreto é, assim, reproduzido pelo pensamento científico, que reconstrói, no plano intelectual, a complexidade das relaçôes que compõem o campo da realidade que constitui o objeto. (DUARTE, 2008, p. 57).

Assim, no processo de escolarização isso se refere à catarse. A atividade de estudo permite aos alunos reproduzirem idealmente os objetos de estudos reais, já existentes na realidade objetiva. Não se cria ou se constrói um objeto de ensino, mas sim se reproduz o objeto de ensino o qual possui existência objetiva. Cabe à escola possibilitar aos alunos a reprodução das determinaçóes e das categorias dos conteúdos de ensino. Isso é feito via processo pedagógico pela transmissão de conteúdos por parte do professor ao aluno. Dessa forma, a catarse "[...] correspondendo aos resultados que tornam possível afirmar que houve aprendizagem, produz, como diria Vigotski, "rearranjos" dos processos psíquicos na base dos quais se instituem os comportamentos complexos, culturalmente formados" (MARTINS, 2013, p. 292). 
O "bom ensino" deve, portanto, reproduzir as formas lógicas e históricas do objeto e do conteúdo de ensino, permitindo a configuração, no plano da educação escolar, daquilo que Marx (2011) afirmou: "A anatomia do homem é a chave para a anatomia do macaco" ${ }^{4}$. Ou seja, o encaminhamento dado pelo autor em termos metodológicos sobre as relaçôes entre o lógico e o histórico se torna fundamentação pedagógica para a pedagogia histórico-crítica.

O método de ensino da pedagogia histórico-crítica busca, assim, conjugar a análise sincrônica do objeto de estudo (sua dinâmica, estrutura e função na forma mais desenvolvida) com a análise diacrônica (a gênese e o desenvolvimento do conteúdo estudado). Em consonância com o método de Marx (2011), para a pedagogia histórico-crítica a forma mais complexa do conteúdo de ensino permite compreender as formas menos complexas de conteúdos escolares sem, entretanto, desconsiderar a necessidade de se conhecer a gênese histórica deste conteúdo mais desenvolvido.

Tal resolução metodológica da pedagogia histórico-crítica inverte a proposição de boa parte das pedagogias dominantes as quais explicitam que o ensino deve partir das formas mais simples para as mais complexas de aprendizado. Com efeito, Marx (2011) assinalou que a forma histórica mais desenvolvida permite a compreensão de todas as formas que a precederam. Este é o critério de desenvolvimento dos conteúdos de ensino que devem ser transmitidos pela educação escolar para esta teoria. $\mathrm{O}$ ensino deve partir dos conteúdos mais desenvolvidos do objeto estudado, percorrer o processo de constituição de sua gênese e desenvolvimento para, por fim, retornar ao ponto de partida, agora compreendido de forma mais concreta.

Tal proposição metodológica permite uma completa diferenciação entre essa teoria pedagógica e a pedagogia tradicional, o que evidencia o quão simplista e equivoca é a percepção que se tem quando se associa a defesa da transmissão dos conteúdos com a pedagogia tradicional.

Ao avançar para além do recurso analítico em si, superando o momento da abstraçáo e percorrendo o caminho de volta (o caminho identificado por Marx como o correto), a pedagogia histórico-crítica reconstrói o objeto de estudo como um todo articulado enriquecido de determinaçóes numerosas, possibilitando e exigindo o enriquecimento do pensamento teórico dos alunos no processo de escolarização. 
Desse modo, tal teoria pedagógica acaba por permitir o cumprimento da função social da educação escolar, ou seja, a reconstrução do conteúdo de ensino num todo articulado à prática social, possibilitando o reconhecimento das determinações essenciais desse conteúdo, determinações estas que operam o conteúdo e são exprimidas pelas categorias, pelos conceitos. Tal processo permite a compreensáo adequada do objeto de estudo e da própria prática social, permitindo aos indivíduos intervirem nesta última de maneira mais qualificada, visando sua transformação.

\section{Considerações finais}

O materialismo histórico-dialético, como fundamento do método pedagógico histórico-crítico é um instrumento lógico de interpretação da realidade, que defende a superação da dicotomia sujeito-objeto, uma vez que compreende o necessário movimento do pensamento. Este só é possível se considerado como desenvolvimento histórico, que constitui a totalidade da prática social, imersa nas contradições da sociedade.

Em termos educativos, poderíamos afirmar que o movimento se dá por meio da organizaçáo sequencial e lógica dos conhecimentos. Um mesmo conteúdo é trabalhado em diferentes momentos da escolarizaçáo do indivíduo, dando a ele cada vez mais elementos à sua síntese de múltiplas determinaçóes. Por exemplo5: o conteúdo "água" pode aparecer desde a Educação Infantil, com características bastante empíricas (identificação, reconhecimento, utilização), passando pelo Ensino Fundamental (ciclo da água, características, estados físicos etc.), chegando ao Ensino Médio, quando o estudo da composição química da água exigirá conhecimentos sobre molécula, átomos, densidade, pressão etc.

No caso da Educação Física, poderíamos citar o ensino do futebol, o qual pode ser tratado como conteúdo desde a Educação Infantil até o Ensino Médio, materializando a espiralidade da incorporação das referências do pensamento, ampliando-se as referências de ensino desse conteúdo de uma unidade a outra, ou de um nível da escolarização a outro (SOARES et al, 1992), tematizando questóes como: o futebol enquanto jogo, suas normas, regras, fundamentos e exigências técnicas e táticas; o futebol enquanto aspecto cultural, associativismo, participação popular e construção de processos identitários de um povo; o futebol como espetáculo esportivo, seus processos de mercantilização e subsunção ao capital; o futebol enquanto atividade de trabalho, atuação 
profissional e organização de classe; dentre outros. Assim, ao longo de todo o processo da educaçáo escolar, pode-se transmitir o conteúdo futebol aos alunos de forma espiralada - devendo o mesmo ocorrer num processo simultâneo com outros conteúdos de ensino -, permitindo a compreensão de que os dados da realidade objetiva que não devem ser pensados tampouco explicados isoladamente, a partir de uma lógica linear ou à luz de um etapismo educacional.

O conjunto de conteúdos que formam a totalidade do currículo escolar se constitui na materialidade histórica que compóe o patrimônio humanogenérico, fruto de séculos de acúmulo de conhecimentos desenvolvidos pelo trabalho humano.

Essa é a função da educação escolar pretendida pela pedagogia históricocrítica: a transformação do sujeito, da sociedade, de forma mediada pela educação. E é nessa função que reside a unidade dos contrários entre ensinar e aprender. Unidade indissolúvel, que nos reforça a ideia marxiana de que contradição não são oposiçóes exteriores, mais interiores uma a outra, que se identificam como necessárias à compreensão de ambas (MARTINS, 2006) e que (adequadamente!) nos impede de separar teoria e prática pedagógica, processos de ensino de processos de aprendizagem.

E o que produzem esses processos? A humanização dos indivíduos. Como isso se dá? Em termos psicológicos, como explica Martins (2013, p. 269):

[...] o desenvolvimento do psiquismo humano identificase com a formação dos comportamentos complexos culturalmente instituídos [que sustentam] a afirmaçáo do ensino sistematicamente orientado à transmissão dos conceitos científicos, não cotidianos, tal como preconizado pela pedagogia histórico-crítica.

Contudo, como alerta a autora, as aprendizagens podem ou não promover o desenvolvimento máximo dos seres humanos. Disso depende a apropriação do patrimônio cultural da humanidade, nas suas formas mais desenvolvidas, enriquecendo o universo de significaçôes dos indivíduos, que possibilite "[...] a elevação para além das significaçóes mais imediatas e aparentes disponibilizadas pelas dimensóes meramente empíricas dos fenômenos" (MARTINS, 2013, p. 272). Nesse sentido, os conteúdos transmitidos pela escola, o grau de complexidade que requerem das açóes do sujeito e a qualidade das mediaçóes para sua realizaçáo, são decisivos no desenvolvimento do psiquismo. 
Vigotskii (2006) já nos ensinou que a aprendizagem não é idêntica e não antecede o desenvolvimento. Ela decorre da instrução, esta sim, como condição para o desenvolvimento. Assim:

[...] entre esses processos [instrução e desenvolvimento] se instala uma relação de condicionabilidade recíproca, explicável à luz do preceito lógico-dialético da dinâmica entre "quantidade e qualidade", ou seja, a "quantidade" de aprendizagens qualifica o desenvolvimento, à mesma medida que a "quantidade" de desenvolvimento qualifica a aprendizagem. O estofo dessa ideia reside na distinção entre formas naturais e primitivas de comportamento e as formas instrumentais, produzidas na história e absolutamente dependentes da aprendizagem. (MARTINS, 2013, p. 278).

Para que essa aprendizagem se dê a bom termo é fundamental a atuação do professor na área de desenvolvimento iminente do aluno. Trata-se, pois, como explica Martins (2013), da superação dos limites de desenvolvimento efetivo do sujeito, agindo planejadamente sobre as pendências cognitivas do indivíduo, o que pressupóe a colaboração do "par mais desenvolvido", que já sintetizou os conhecimentos necessários à humanizaçáo do outro. Assim, essa não é uma tarefa de mera interação entre sujeitos, pois se estabelece na dependência da qualidade das mediaçóes que o par mais desenvolvido realiza, alterando um funcionamento, de interpsicológico para intrapsicológico:

Portanto, um ensino apto a organizar-se levando em conta o nível de desenvolvimento real e a área de desenvolvimento iminente requer uma sólida formação de professores, que os instrumentalize teórica e metodologicamente para a assunção da complexa tarefa representada nos processos de ensino e aprendizagem. (MARTINS, 2013, p. 288).

O espírito do qual se imbui a pedagogia histórico-crítica é, pois, da valorizaçáo do professor, do ensino intencionalmente planejado, da transmissáo da cultura, visando a humanizaçáo plena dos indivíduos. Nesse sentido, compreender o método pedagógico dessa teoria em consonância com os fundamentos do materialismo histórico-dialético é essencial para sua realização bem sucedida e coerente com sua proposição. 


\section{Notas}

${ }^{1}$ Importante lembrar que, conforme Netto (2011), neste momento Marx reconhece suas limitaçóes teóricas para a busca da compreensão do problema com o qual se depara e, percebendo a necessidade de seu enriquecimento teórico (para compreender e solucionar os problemas da prática), passa a estudar intensivamente todo um apanhado de livros, textos e obras clássicas em busca de formação intelectual, filosófica e política. Tal fato parece elucidar o encaminhamento correto da pedagogia histórico-crítica ao defender a transmissão do saber elaborado na educação escolar como forma de contribuir para que os indivíduos elevem seu pensamento a uma condição indispensável de domínio do instrumental lógico o qual garanta ao pensamento captar a realidade concreta nas suas intrínsecas relaçóes recíprocas e, dessa maneira, permita-os operar mudanças na realidade social (OLIVEIRA, 1996).

${ }^{3}$ Marx e Engels (2007, p. 537, grifo do autor) assim formulou sua segunda tese contra Feuerbach: "A questáo de saber se ao pensamento humano cabe alguma verdade objetiva não é uma questão da teoria, mas uma questão prática. Na prática tem o homem de provar a verdade, isto é, a realidade e o poder, a natureza citerior de seu pensamento. A disputa acerca da realidade ou não-realidade de um pensamento que se isola da prática é uma questão puramente escolástica”.

${ }^{4}$ Saviani (2008a) já apontara no livro Pedagogia histórico-crítica: primeiras aproximaçōes que é tarefa da educação escolar identificar as formas mais desenvolvidas em que se expressa o saber objetivo e convertê-lo em saber escolar, de modo a torná-lo assimilável pelos alunos, apreendendo o processo de sua produçấo e suas tendências de transformação.

${ }^{4}$ Nunca é demais lembrar a famosa tese de Marx (2011, p. 58), cuja análise lógica da forma mais desenvolvida é a chave para a plena compreensão das formas precedentes: "A sociedade burguesa é a mais desenvolvida e diversificada organização histórica da produção. Por essa razão, as categorias que expressam suas relações e a compreensão de sua estrutura permitem simultaneamente compreender a organização e as relaçốes de produção de todas as formas de sociedades desaparecidas, com cujos escombros e elementos edificou-se, parte dos quais ainda carrega consigo 
como resíduos não superados, parte [que] nela se desenvolvem de meros indícios em significações plenas etc. A anatomia do ser humano é uma chave para a anatomia do macaco. Por outro lado, os indícios de formas superiores nas espécies animais inferiores só podem ser compreendidos quando a própria forma superior já é conhecida. Do mesmo modo, a economia burguesa fornece a chave da economia antiga etc. Mas de modo algum à moda dos economistas, que apagam todas as diferenças históricas e vêem a sociedade burguesa em todas as formas de sociedade".

${ }^{5}$ Exemplo dado por Lígia Márcia Martins (2013), no II Encontro de Educadores de Limeira (SP), realizado pela Secretaria Municipal de Educação, em 24 de julho de 2013.

\section{REFERÊNCIAS}

BATISTA, Eraldo Leme; LIMA, Marcos R. A pedagogia históricocrítica como teoria pedagógica transformadora: da consciência filosófica à prática revolucionária. In: MARSIGLIA, Ana Carolina Galvão; BATISTA, Eraldo Leme (Org.). Pedagogia histórico-critica: desafios e perspectivas para uma educação transformadora. Campinas, SP: Autores Associados, 2012. p. 1-36.

DUARTE, Newton. Sociedade do conhecimento ou sociedade das ilusóes? Quatro ensaios crítico-dialéticos em filosofia da educação. Campinas, SP: Autores Associados, 2008.

DUARTE, Newton. Fundamentos da pedagogia histórico-crítica: a formação do ser humano na sociedade comunista como referência para a educação contemporânea. In: MARSIGLIA, Ana Carolina Galvão (Org.). Pedagogia histórico-critica: 30 anos. Campinas, SP: Autores Associados, 2011. p. 7-22.

HUNGARO, Edson Marcelo. Trabalho, tempo livre e emancipação humana: os determinantes ontológicos das políticas sociais de lazer. 2008. Tese (Doutorado em Educação Física) - Universidade Estadual de Campinas, Campinas, SP, 2008. 
MARTINS, Lígia Márcia. As aparências enganam: divergências entre o materialismo histórico dialético e as abordagens qualitativas de pesquisa. In: REUNIÃO ANUAL DA ANPED, 29., 2006, Caxambu. Anais... Caxambu, MG: Anped, 2006. Disponível em: <http://www.anped.org.br/ reunioes/29ra/trabalhos/trabalho/GT17-2042--Int.pdf>. Acesso em: 1 mar. 2011.

MARTINS, Lígia Márcia. Pedagogia histórico-crítica e psicologia históricocultural. In: MARSIGLIA, Ana Carolina Galvão (Org.). Pedagogia históricocritica: 30 anos. Campinas, SP: Autores Associados, 2011. p. 43-58.

MARTINS, Lígia Márcia. O desenvolvimento do psiquismo e a educação escolar: contribuiçóes à luz da psicologia histórico-cultural e da pedagogia histórico-crítica. Campinas, SP: Autores Associados, 2013.

MARX, Karl. Contribuição à crítica da economia política. 2. ed. São Paulo: Expressão Popular, 2008a.

MARX, Karl. O capital: crítica da economia política - o processo de produção do capital. 26. ed. Rio de Janeiro: Civilização Brasileira, 2008b. Livro 1, v. 1.

MARX, Karl. Grundrisse: manuscritos econômicos de 1857-1858. São Paulo: Boitempo, 2011.

MARX, Karl; ENGELS, Friedrich. A ideologia alemã. São Paulo: Boitempo, 2007.

NETTO, José Paulo. Introdução ao estudo do método de Marx. São Paulo: Expressão Popular, 2011.

OLIVEIRA, Betty. O trabalho educativo: reflexôes sobre paradigmas e problemas do pensamento pedagógico brasileiro. Campinas, SP: Autores Associados, 1996.

OLIVEIRA, Betty. A dialética do singular-particular-universal. In: ABRANTES, Angelo A.; SILVA, Nilma R.; MARTINS, Sueli T. Ferreira. Método histórico-social na Psicologia Social. São Paulo: Vozes, 2005. p. 25-51.

SAVIANI, Dermeval. Educação: do senso comum à consciência filosófica. 13. ed. Campinas, SP: Autores Associados, 2000. 
SAVIANI, Dermeval. Pedagogia histórico-critica: primeiras aproximaçóes. 10. ed. Campinas, SP: Autores Associados, 2008a.

SAVIANI, Dermeval. Educação socialista, pedagogia histórico-crítica e os desafios de uma sociedade de classes. In: LOMBARDI, José Claudinei; SAVIANI, Dermeval (Org.). Marxismo e Educação: debates contemporâneos. 2. ed. Campinas, SP: Autores Associados, 2008b. p. 223-274.

SAVIANI, Dermeval. Escola e democracia. 41. ed. Campinas, SP: Autores Associados, 2009.

SAVIANI, Dermeval. História das ideias pedagógicas no Brasil. 3. ed. Campinas, SP: Autores Associados, 2011.

SAVIANI, Dermeval. Marxismo, educação e pedagogia. In: SAVIANI, Dermeval; DUARTE, Newton (Org.). Pedagogia histórico-critica e luta de classes na educação escolar. Campinas, SP: Autores Associados, 2012. p. 5985.

SAVIANI, Dermeval; DUARTE, Newton (Org.). Pedagogia histórico-crítica e luta de classes na educação escolar. Campinas, SP: Autores Associados, 2012.

SILVA, Tomaz Tadeu da. Documentos de identidade: uma introdução às teorias do currículo. Belo Horizonte: Autêntica, 1999.

SOARES, Carmen Lucia et al. Metodologia do ensino de Educação Física. São Paulo: Cortez, 1992.

VIGOTSKII, Lev S. Aprendizagem e desenvolvimento intelectual na idade escolar. In: VIGOTSKII, Lev S.; LURIA, Alexander R.; LEONTIEV, Alexei. N. Linguagem, desenvolvimento e aprendizagem. 10. ed. Sáo Paulo: Ícone, 2006. p. 103-117. 


\section{La pedagogía histórica- crítica y la defensa de la transmisión del saber elaborado: anotaciones sobre el método pedagógico}

\section{Resumen}

El objetivo del artículo es realizar una discusión sobre el método pedagógico de la pedagogía histórica-crítica, explicado en las bases de su fundamentación referenciada en el Método de la Economía Política elaborado por Marx en la famosa Introducción de 1857. De este modo, se explicita el movimiento del conocimiento como el paso de lo empírico a lo concreto a través de la mediación de lo abstracto, resaltando el carácter mediador de la educación en la práctica social, tomándola como punto de partida y punto de llegada del trabajo educativo, teniendo como momentos intermedios del método pedagógico el problematizar esta práctica social, la instrumentalización a través de la transmisión de los conocimientos en sus formas más elaboradas y la catarsis, como síntesis de desarrollo del alumno y, como consecuencia, la posibilidad de alteración de la práctica social humana-genérica. De este modo, se busca mostrar la lógica dialéctica de esta propuesta pedagógica que aboga la actividad de enseñanza en la educación escolar como aquella responsable por la reproducción ideal del movimiento real de los contenidos escolares, lo que permite el alcance de la riqueza categórica de los objetos de

\section{Historical-critical pedagogy and the defense of elaborate knowledge transmission: notes on pedagogical method}

\section{Abstract}

This article aims to carry out a discussion about pedagogical method of historicalcritical pedagogy, clearly highlighting its fundaments on Political Economy Method, created by Karl Marx in his famous 1857. Thus, the study seeks to make clear the dialectical logic of this pedagogical proposal that speaks up for the teaching activity in school education as that responsible by the ideal reproduction of the real school subjects movement, enabling the reach of categorical wealth of teaching objects as synthesis of multiple determinations and numerous relationship. So, it is made explicit the movement of knowledge as the passage from the empirical to the concrete by abstract mediation, highlighting the mediating character of education in social practice, taking this as a starting point and end point of the educational work, taking the questioning of this social practice as intermediate moments of pedagogical method, the manipulation through the transmission of knowledge in its most elaborate forms and catharsis as student development synthesis and consequently the possibility of changing humangeneric social practice. In this sense, understanding the pedagogical method of this theory founded on HistoricalDialectical Materialism is essential to 
enseñanza, como síntesis de múltiples determinaciones y relaciones numerosas. En este sentido, comprender el método pedagógico de esta teoría en consonancia con los fundamentos del materialismo histórico-dialéctico es esencial para su éxito y coherencia con su proposición.

Palabras claves: Educación Escolar. Pedagogía histórica-crítica. Método Dialéctico. successfully and coherently carry out its proposition.

Keywords: School Education. Historicalcritical Pedagogy. Dialectical Method.

\section{Tiago Nicola Lavoura}

E-mail:nicolalavoura@uol.com.br

\section{Ana Carolina Galvão Marsiglia}

E-mail: galvao.marsiglia@gmail.com

Enviado em: 24/9/2014

Aprovado em: 17/11/2014 